\title{
Role of the Polymorphonuclear Leukocyte: Interaction with Nosocomial Pathogens
}

Advances in our understanding of the role of neutrophils in lung defense have occurred in several cycles over the past century. By the turn of the century, the concept of an antibacterial defense mechanism intrinsic to the lung was well established. Although it was recognized by the early 1900 s that polymorphonuclear leukocytes were prominent phagocytes in the lungs of persons dying of bacterial pneumonia, these cells were widely believed to play no role in the eradication of most bacterial challenges. The pulmonary antibacterial defenses were believed to be dependent on large, phagocytic mononuclear cells recruited to the air spaces from alveolar walls in response to bacteria. The phagocytic activity of mononuclear cells was believed to be sufficient for most challenges; circulating leukocytes were involved only when mononuclear cells were unable to handle the challenge (1).

\section{Phagocytic Cells Involved in Pulmonary Bacterial Clearance}

The concept of a pulmonary defense mechanism against bacteria was extended in a series of elegant studies on the histogenesis of pneumonia $(2-11)$. While quantitative bacteriologic methods were not utilized in these studies, large numbers of polymorphonuclear leukocytes were demonstrated in alveolar spaces 1.5 hours after bacterial inoculation. The importance of these polymorphonuclear leukocytes in lung defense against bacteria was suggested by photomicrographs showing free polymorphonuclear leukocytes phagocytosing organisms in alveolar spaces $(10,11)$. With the development of quantitative aerosol inoculation techniques, it became possible to study the ability of the lung to clear bacteria over time (12-14). Aerosolized Staphylococcus aureus $\left(5 \times 10^{4}\right)$ did not evoke a polymorphonuclear leukocyte response. All intracellular organisms identified by light microscopy within 4 hours of inoculation were found inside alveolar macrophages $(13,15)$. Similar results were reported for Proteus mirabilis (13). These investigations concluded that the alveolar macrophage was the principle defender of the lung against bacteria.

The first observation that aerosol inoculation of bacteria could result in a polymorphonuclear leukocyte response was made in experiments in which approximately $8 \times 10^{4}$ Pseudomonas aeruginosa were inoculated into the lung (16). The phagocytic response has subsequently been quantified in studies using both histological and bronchoalveolar lavage techniques $(17,18)$. While polymorphonuclear leukocytes played no role in the pulmonary clearance of inocula of up to $4 \times 10^{6}$ Staphylococcus aureus, aerosols of gram-negative bacteria elicited an impressive polymorphonuclear leukocyte inflammatory response in bronchi and alveoli. An additional determinate of a polymorphonuclear leukocyte response was the inoculum size $(18,19)$. Following aerosol and bolus inoculation, both bacterial clearance and the magnitude of the polymorphonuclear leukocyte response were related to the number of bacteria deposited in the lung. Thus, the generation of a polymorphonuclear leukocyte response following bacterial inoculation was dependent on the bacterial species and the inoculum size. These studies indicated that both alveolar macrophages and polymorphonuclear leukocytes were involved in lung defense against pathogenic organisms. The relative importance of each phagocyte was uncertain. The functional significance of the recruited polymorphonuclear leukocytes was demonstrated by selective depletion of polymorphonuclear leukocytes. Neutropenic animals cleared inocula of Streptococcus pneumoniae, Pseudomonas aeruginosa, Klebsiella pneumoniae and Haemophilus influenzae (20-22). Neutropenic animals could not clear gram-negative organisms, even in the presence of antibiotics (20).

These observations demonstrate that a dual phagocytic system is involved in pulmonary antibacterial responses. While alveolar macrophages can clear certain inocula of bacteria, an inflammatory response is usually generated by pathogenic organisms. Following an inoculation with virulent organisms, polymorphonuclear leukocytes recruited from the circulation are required for effective clearance of the organisms. Thus, the ability to rapidly recruit polymorphonuclear leukocytes into the pulmonary parenchyma represents a major component of the early defense against most bacteria.

\section{Recruitment of Polymorphonuclear Leukocytes}

Polymorphonuclear leukocytes are rare in the air spaces of normal lungs (23) and represent less than $2 \%$ of the cells present in normal bronchoalveolar lavage fluid. It is likely that the presence of bacteria 
in alveolar spaces triggers the generation of chemotactic factors, which are responsible for polymorphonuclear leukocyte accumulation in the lung within the air spaces or the interstitium of the lung. Chemotactic activity has been demonstrated in bronchoalveolar lavage fluids following intrapulmonary inoculation of both gram-positive and gram-negative organisms $(22,24,25)$. Increases in chemotactic activity preceded the accumulation of polymorphonuclear leukocytes. Furthermore, the number of polymor. phonuclear leukocytes and the amount of chemotactic activity in bronchoalveolar lavage fluids could be correlated. Thus, the generation of chemotactic factors in the pulmonary air spaces appears to mediate the rapid recruitment of polymorphonuclear leukocytes.

Potential chemotactic factors are shown in Table 1. The role of the complement system in polymorpho. nuclear leukocyte recruitment has been evaluated using congenic $\mathrm{C} 5$ sufficient $(\mathrm{C} 5+)$ and $\mathrm{C} 5$ deficient (C5-) mice, which differ only at the locus that determines the presence or absence of the $\mathrm{C} 5$ molecule (26). Products of the C5 molecule have been shown to be important in polymorphonuclear leukocyte recruitment in murine lungs following inoculation with gram-positive and gram-negative bacteria (27, 28). The mechanism responsible for cleavage of $\mathrm{C5}$ in the lung is unknown. Bacteria might generate C5 fragment by activation of an alternative pathway. Alternatively, proteinases derived from alveolar macrophages or neutrophil granules might cleave C5 without activation of the remainder of the complement pathway $(29,30)$.

Chemotaxins other than $\mathrm{C} 5$ fragments have also been demonstrated to be important in polymorphonuclear leukocyte recruitment following bacterial challenge. No differences in polymorphonuclear leukocyte recruitment were found in $\mathrm{C} 5+$ and $\mathrm{C} 5-$ mice follow-

Table 1: Potential chemotactic factors involved in neutrophil recruitment.

\begin{tabular}{l} 
Complement pathway \\
C5A, C5A des Arg \\
Fibrinolytic/kinin path way \\
kallikrein \\
plasminogen activator \\
Macrophages \\
AMCFN \\
5-HETE \\
11-HETE \\
leukotriene $B_{4}$ \\
platelet activating factor \\
Granulocyte products \\
cell-derived, stable \\
conversion of C5 to C5a \\
Products of bacterial growth \\
\hline
\end{tabular}

ing inoculation of $10^{6}$ or $10^{7}$ Staphylococcus aureus (25). Additionally, following gram-negative bacterial challenge $\mathrm{C} 5$-mice generated significant but delayed polymorphonuclear leukocyte responses that were associated with significant levels of chemotactic activity in bronchoalveolar lavage fluid $(22,28)$. The chemotaxin(s) involved in the recruitment of polymorphonuclear leukocytes following challenge with Staphylococcus aureus probably include alveolar macrophage-derived chemotactic factor for neutrophils activity $(31,32)$ and/or macrophage-generated products of the lipoxygenase pathway $(33-36)$. Additionally, alveolar macrophages generate plateletactivating factor $(37,38)$ and plasminogen activator (39), which may function as chemotaxins. Secreted products from recruited polymorphonuclear leukocytes may also have important roles (40-43), particularly in the later phases of the response. Finally, chemotaxins generated by bacteria might be also involved (44-46).

In summary, recruitment of polymorphonuclear leukocytes following bacterial challenge to the lung involves multiple chemotaxins. The importance of these chemotaxins likely varies for differing bacterial species. Additionally, it is likely that more than one pathway is involved for any given bacterium. Complement components are important in the initial 4 to 6 hours of the response for most but not all bacteria. Chemotactic factors other than complement are present in the air spaces. These factors are important in the later $(12-24 \mathrm{~h})$ phases of the response and are probably involved in the early responses as well.

While the major components involved in the generation of the inflammatory response are being identified, large gaps in our knowledge exist. Little is known about the regulatory events that control cell-secreted chemotaxins. Further studies of the genetic regulation of these chemotactic factors as well as other amplifying and inhibiting factors are required. Additionally, the physical properties of chemotaxins have not been studied. Studies to assess lipid solubility, molecular size, charge and diffusability are needed. Until these studies are performed, it will be difficult to determine whether chemotactic factors can actually cross the alveolar epithelium and pulmonary interstitium and reach the circulation to attract inflammatory cells.

\section{G. B. Toews}

Division of Pulmonary and Critical Care Medicine, Department of Internal Medicine, University of Michigan Medical Center, 3916 Taubman Center, 1500 East Medical Center Drive, Ann Arbor, Michigan 48109-0360, USA. 


\section{References}

1. Briscoe, J.C.: An experimental investigation of the phagocytic action of the alveolar cells of the lung. Journal of Pathology and Bacteriology 1908, 12: 66100.

2. Stillman, E. G.: The presence of bacteria in the lungs of mice following inhalation. Journal of Experimental Medicine 1923, 38: 117-126.

3. Stillman, E. G., Branch, A.: Experimental production of pneumococcus pneumonia in mice by the inhalation method. Journal of Experimental Medicine 1924, 40: $733-742$.

4. Wood, W. B.: Studies on the mechanism of recovery in pneumococcal pneumonia. I: The action of type specific antibody upon the pulmonary lesion of experimental pneumonia. Journal of Experimental Medicine 1941, 73: $201-222$.

5. Wood, W. B., Irons, E.N.: Studies on the mechanism of recovery in pneumococcal pneumonia. II: The effect of sulfonamide therapy upon the pulmonary lesion of experimental pneumonia. Journal of Experimental Medicine $1946,84: 365-376$.

6. Wood, W. B., McLeod, C., Iron, E. B.: Studies on the mechanism of recovery in pneumococcal pneumonia. III: Factors influencing the phagocytosis of pneumococci in the lung during sulfonamide therapy. Journal of Experimental Medicine 1946, 84: 377-386.

7. Wood, W. B., Smith, M. R., Watson, B.: Studies on the mechanism of recovery in pneumococcal pneumonia. IV: The mechanism of phagocytosis in the absence of antibody. Journal of Experimental Medicine 1946, 84: $387-402$.

8. Wood, W. B., Smith, M.R.: Host-parasite relationships in experimental pneumonia due to pneumococcus type III. Journal of Experimental Medicine 1950, 92: 85-99.

9. Sale, L., Wood, W. B.: Studies on the mechanism of recovery in pneumonia due to Friedlander's bacillus. I: Pathogenesis of experimental Friedlander's bacillus pneumonia. Journal of Experimental Medicine 1944, 86: $239-247$.

10. Loosli, C. G.: The histogenesis of cells in experimental pneumonia in the dog. Journal of Experimental Medicine 1942,$75 ; 657-672$.

11. Loosli, C.G.: The pathogenesis and pathology of experimental type I pneumococci pneumonia in the monkey. Journal of Experimental Medicine 1942, 76: $79-92$.

12. Laurenzi, G. A., Berman, L., First, M., Kass, E. H.: A quantitative study of the deposition and clearance of bacteria in the murine lung. Journal of Clinical Investigation 1964, 43: 759-768.

13. Green, G. M., Kass, E. H.: The role of the alveolar macrophage in the clearance of bacteria from the lung. Journal of Experimental Medicine 1964, 119: 167-176.

14. Green, G. M., Kass, E. H.: Factors influencing clearance of bacteria by the lung. Journal of Clinical Investigation $1969,43: 769-776$.

15. Goldstein, E., Lippert, W., Warshauer, D.: Pulmonary alveolar macrophage. Defender against bacterial infection of the lung. Journal of Clinical Investigation 1974, 54: $519-528$.

16. Jackson, A.E., Pierce, A. K., Southern, P., Sanford, J.P.: Pulmonary clearance of gram-negative bacilli. Journal of Laboratory and Clinical Medicine 1967, 69: $833-841$.

17. Pierce, A. K., Reynolds, R. C., Harris, G. D.: Leukocytic response to inhaled bacteria. American Review of Respiratory Disease 1977, 116: 679-684.

18. Toews, G. B., Gross, G. N., Pierce, A. K.: The relationship of inoculum size to lung bacterial clearance and phagocytic cell response in mice. American Review of Respiratory Disease 1979, 120: 559-566.

19. Onofrio, J. M., Toews, G. B., Lipscomb, M. F., Pierce, A. K.: Granulocyte-alveolar macrophage interaction in the pulmonary clearance of Staphylococcus aureus. American Review of Respiratory Disease 1983, 127 335-341.

20. Dale, R. C., Reynolds, H. Y., Pennington, J. E., Elin, R.J., Pitts, T.W., Graw, R.G.: Granulocyte transfusion therapy of experimental Pseudomonas pneumonia. Journal of Clinical Investigation 1974, 54: 664-671.

21. Rehm, S. R., Gross, G.N., Pierce, A. K.: Early bacterial clearance from murine lungs. Species dependent phagocyte response. Journal of Clinical Investigation 1980 , 6: 194-199.

22. Toews, G. B., Vial, W. C., Hansen, E.J.: Role of C5 and recruited neutrophils in early clearance of nontypable Haemophilus influenzae from murine lungs. Infection and Immunity 1985, 50: 207-212.

23. Cohen, A., Batra, G., Petersen, R., Podanay, J., Nguyen, D.: Size of the pool of alveolar neutrophils in normal rabbit lungs. Journal of Applied Physiology 1979, 47: $440-444$

24. Vial, W. C., Toews, G. B., Pierce, A. K.: Early pulmonary granulocyte recruitment in response to Streptococcus pneumoniae. American Review of Respiratory Disease 1984, 129: 87-91

25. Toews, G.B., Pierce, A.K.: The fifth component of complement is not required for the clearance of Staphyl. ococcus aureus. American Review of Respiratory Disease 1984, 129: 597-601.

26. Nilsson, U.R., Muller-Eberhard, H.J.: Deficiency of the fifth component of complement of mice with an inherited complement defect. Journal of Experimental Medicine 1967, 125: 1-16.

27. Toews, G. B., Vial, W.C.: The role of C5 in polymorphonuclear leukocyte recruitment in response to Streptococcus pneumonia. American Review of Respiratory Disease 1984, 129: 82-86.

28. Larsen, G. L., Mitchell, B. C., Harper, T. B., Henson, P.M.: The pulmonary response of $\mathrm{C5}$ sufficient and deficient mice to Pseudomonas aeruginosa. American Review of Respiratory Disease 1982, 126: 306-311.

29. Snyderman, R., Shin, H.S., Dannenberg, A. M.: Macrophage proteinase and inflammation. The production of chemotactic activity from the fifth component of complement by macrophage proteinase. Journal of $\mathbf{I m}$ munology 1972, 109: 896-898.

30. Ward, P. A., Hill, H.J.: C5 chemotactic fragments produced by an enzyme in lysosomal granules of neutrophils. Journal of Immunology 1970, 104: 535-543.

31. Merrill, W.W., Naegel, G.P., Mattay, R. A., Reynolds, H. Y.: Alveolar macrophage-derived chemotactic factor, kinetics of in vitro production and partial characterization. Journal of Clinical Investigation 1980, 65: 268276.

32. Hunninghake, G.W., Gadek, J.E., Fales, H. M., Crystal, R. G.: Human alveolar macrophage-derived chemotactic factor for neutrophils, stimuli and partial characterization. Journal of Clinical Investigation 1980, 66: 473483.

33. Valone, F.H., Franklin, M., Sun, F, F., Goetzl, E. J.: Alveolar macrophage lipoxygenase products of arachidonic acid. Isolation and recognition as the predominant constituents of the neutrophil chemotactic activity elaborated by alveolar macrophages. Cellular Immunology 1980, 54:390-401.

34. Fels, A. O.S., Pawlowski, N. A., Cramer, E. B., King, T. K. C., Cohn, Z.A., Scott, W. A.: Human alveolar macrophages produce leukotriene $B_{4}$. Proceedings of the National Academy of Sciences of the USA 1982, 79: $786-787$ 
35. Martin, T. R., Altman, L. C., Albert, R. K., Henderson, W.R.: Leukotriene $B_{4}$ production by human alveolar macrophages. A potential mechanism for amplifying inflammation in the lung. American Review of Respiratory Disease 1984, 129: 106-111.

36. Wessalius, L. J., Catanzaro, A., Wasserman, S. I.: Neutrophil chemotactic activity generation by alveolar macrophages after bleomycin injury. American Review of Respiratory Disease 1984, 129:485-490.

37. Arnoux, B. A., Duval, D., Benveniste, J.: Release of platelet activating factor from alveolar macrophages by the calcium ionophore A23187 and phagocytosis. European Joumal of Clinical Investigation 1980, 10: $437-441$.

38. Parente, L., Fitzgerald, M., De-Nucci, G., Moncada, S.: The release of lyso-platelet activating factor from guinea pig lungs. European Journal of Pharmacology 1985, 112: $281-284$.

39. Fels, A. O.S., Cohn, Z.A.: The alveolar macrophage. Journal of Applied Physiology 1986, 60: 353-369.

40. Wright, D. G., Gallin, J.I.: A functional differentiation of human neutrophil granules. Generation of C5a by a specific (secondary) granule product and inactivation of C5a by azurophil (primary) granule products. Journal of Immunology 1977, 119: 1068-1076.
41. Gallin, J. I., Wolff, S. M.: Leukocyte chemotaxis. New methods for evaluation and demonstration of a cell derived chemotactic factor. Journal of Experimental Medicine 1975, 4: 567-607.

42. Zigmond, S. H., Hirsch, J. C.: Leukocyte locomotion and chemotaxis. New methods for evaluation and demonstration of a cell derived chemotactic factor. Journal of Experimental Medicine 1973, 137: 387-410.

43. Phelps, P.: Polymorphonuclear leukocyte motility in vitro. III: Possible release of a chemotactic substance after phagocytosis of urate crystals by polymorphonuclear leukocytes. Arthritis and Rheumatism 1969 , 12: $197-204$.

44. Keller, H. U., Sorkin, E.: Studies on chemotaxis. V: On the chemotactic effects of bacteria. International Archives of Allergy 1967, 31: 505-517.

45. Ward, P. A., Lepow, I. H., Newman, L.J.: Bacterial factors chemotactic for polymorphonuclear leukocytes. American Journal of Pathology 1968, 52: 725736.

46. Schiffman, E., Corcoran, B. A., Wahl, S. M.: N-formylmethionyl peptides as chemoattractants for leukocytes. Proceedings of the National Academy of Sciences of the USA $1975,72: 1059 \ldots 1062$. 